\title{
Inequality and Growth: A Semiparametric Investigation
}

\author{
Dustin Chambers* \\ Salisbury University
}

Latest Revision: January 26, 2005

\begin{abstract}
The relationship between income inequality and economic growth is re-examined using a semiparametric, dynamic panel data model. Significant empirical evidence is uncovered supporting the theory that the relationship between these variables is nonlinear. Additionally, the evidence also supports the conclusion that other important economic variables, notably past inequality and the rate of investment, directly affect the relationship between base period inequality and subsequent 5-year growth. The results of this paper suggest that higher income inequality (regardless of the magnitude of change) and small reductions in income inequality both reduce subsequent growth. Interestingly, large reductions in income inequality are growth promoting. Moreover, it is found that lower investment rates mitigate the negative effects of higher inequality on growth. It is shown that these results, collectively, are consistent with both a simple political economy model with costly bargaining and an economic growth model with capital-skill complementarities and imperfect credit markets.
\end{abstract}

Keywords: Economic Growth, Income Inequality, Capital-Skill Complementarity, Semiparametric Dynamic Panel

JEL Classifications: E22, H52, O40

\footnotetext{
* Department of Economics and Finance, Salisbury University, Holloway Hall, 1101 Camden Ave., Salisbury MD 21801-6860, e-mail: DLChambers@salisbury.edu, Internet: www.dustinchambers.com. I would like to thank Kenneth Baerenklau, Paul Beaudry, Oded Galor, Jang-Ting Guo, Daniel Henderson, Alan Krause, Tae-Hwy Lee, Robert Russell, and Aman Ullah for their helpful comments, discussions, and suggestions. Any remaining errors are my own.
} 


\section{$1 \quad$ Introduction}

Does the distribution of income impact the rate of economic growth? The answer to this question has obvious and important implications for policy makers. As a result, it is not surprising that economists have vigorously debated the answer to this question and in the process have produced a large body of work, including a wealth of both theoretical models and empirical studies. Unfortunately, little consensus has emerged regarding the true relationship between inequality and growth. This lack of consensus, as it pertains to empirical studies, can be explained in part by differences in growth horizons, conditioning variables, estimation techniques, data, and the functional form of the regression models. This paper will focus on the latter two issues, and in particular will demonstrate that flexible estimation techniques, which allow for nonlinearity in the conditional mean of the economic growth rate, produce results that are contrary to much of the recent literature. But before exploring this paper's results in more detail, it is helpful to briefly summarize the results of the existing literature.

In 1994, Persson and Tabellini, and Alesina and Rodrik independently produced cross-sectional models where the long-run economic growth rate over the time period in question (20 to 25 years) was explained by a linear set of variables measured at the beginning of the time period. Despite differences in variable definitions and conditioning variables, both papers reached similar conclusions: initial income inequality is harmful to subsequent, long-run economic growth. ${ }^{1}$ Several other papers, seeking to improve upon the basic models employed above, were published in the 1990s with similar results (see Clarke (1995) and Alesina and Perotti (1996)). However, this empirical regularity was seriously challenged by the introduction of the Deininger and Squire (1996) panel dataset on income inequality. ${ }^{2}$

Making use of the Deininger and Squire (1996) panel data set, Li and Zou (1998) and Forbes (2000) developed fixed effects versions of existing cross-country growth models. Both papers found a positive and statistically significant relationship between beginning of period income inequality and subsequent 5-year economic growth. These results were robust to minor changes in the models, including differences in inequality measurement (i.e. gini coefficients, income shares). ${ }^{3}$ However, other panel data investigations did not find a positive relationship between inequality and growth. 
Using three-stage least squares, Barro (2000) estimated a random effects panel system and found that the relationship between inequality and subsequent 10-year economic growth was statistically insignificant. Exploring this relationship further, however, Barro found that inequality promoted growth in wealthier nations, and reduced growth in poorer nations. This discrepancy between Barro (2000) and Forbes (2000), could conceivably be a reflection of differences in modeling country-specific effects (i.e. the use of random versus fixed effects), the length of time horizons used (10-year versus 5-year subsequent growth), the use of differing subsets of the Deininger and Squire (1996) panel data set (Forbes exclusively used the "high quality" portion of the dataset while Barro used a much larger dataset that included observations with vague or unidentified primary sources), and to a lesser extent differences in control variables (Forbes' model does not include a policy variable representing government spending, conditional convergence, inflation or capital investment). ${ }^{4}$ However, Banerjee and Duflo (2003) argue quite convincingly that the true reason for the numerous differences in the existing literature stems from a single problem: neglected nonlinearity.

Banerjee and Duflo (2003) demonstrated that if there exist nonlinear relationships between income inequality (and/or changes in income inequality) and subsequent economic growth, and if a linear model is mistakenly used to estimate this relationship, then the estimated reduced form coefficients of the linear model are actually functions of the unidentified structural coefficients of the non-linear model. Depending upon the specification of the linear model (e.g. fixed or random effects, and the included conditioning variables), positive or negative estimated (reduced form) coefficients on inequality reflect different underlying functions of the actual structural parameters. They found strong evidence that nonlinear relationships between 1) changes in income inequality and growth and 2) lagged income inequality and growth, exist in the data, supporting their assertion that the previous literature suffers from significant misspecification problems. In particular, they found that changes in income inequality, regardless of the direction, reduce economic growth. Additionally, they found no relationship between beginning of period inequality and subsequent growth, but they did not find a negative relationship between lagged income inequality and subsequent growth.

This paper, while similar to Banerjee and Duflo (2003) in some aspects, differs in two crucial ways: First, this paper investigates whether factors in addition to 
income inequality impact economic growth in a non-linear way, and second, the current this paper uses a fixed effects panel instead of a random effects panel.

As a result of this alternative and more flexible specification, it will be shown that both increases in income inequality (regardless of the magnitude) and small reductions in income inequality reduce economic growth rates, but that large reductions in inequality actually bolsters economic performance. While not inconsistent with the political economy model discussed in Section 2 below, it does suggest that the nature of political bargaining processes (and their impact on economic performance) may be more complicated than first suspected. In addition, the results of this paper are also consistent with several of the implications of class of economic growth models with capital-skill complementarity. First, it is shown that less developed nations experience lower reductions in growth as the result of an increase income inequality. Second, it is shown that as a nation develops, the impact of changes in the distribution of income on economic performance diminishes.

The remainder of the paper is organized as follows: Section 2 will briefly outline two important channels through which inequality can impact growth. Section 3 will layout the empirical methodology and data used in this paper. Section 4 will estimate the semiparametric model used in this paper and discuss the results. Finally, Section 5 will conclude.

\section{Nonlinear Channels between Inequality and Growth}

In the absence of very strong assumptions regarding political processes, technology, preferences, endowments, the convexity of the factors of production (e.g. capital), and the completeness of markets, Banerjee and Duflo (2003) demonstrate that there is no reason to assume that the relationship between income inequality and economic growth is linear. That being said, this paper will focus on two non-linear mechanisms through which inequality can impact growth: 1) an elementary political economy bargaining model, and 2) a growth model with physical and human capital complementarity.

\subsection{Political Economy Bargaining Model}

Banerjee and Duflo (2003) discuss an elementary "hold-up" model whereby two competing groups engage in costly negotiations regarding the implementation of growth promoting reforms (or investments) and the subsequent distribution of income. If a given group (chosen at random) chooses to forego negotiations and immediately 
implement the growth promoting reform, the full growth-potential of that reform will be realized and the status quo distribution of income will prevail. However, if the same randomly chosen group instead decides to engage in negotiations, they may increase their share of the nation's income but the resulting growth rate will be lower. If the reform/investment is not implemented, the distribution of income will remain unchanged and no economic growth will occur. This bargaining game implies the relationship between income inequality and subsequent growth takes the following form:

$$
g r_{i t+5}=\alpha_{i}+\beta_{1} y_{i t}+k\left(g_{i n i}-g i n i_{i t-5}\right)+X_{i t} B+\varepsilon_{i t}
$$

where $\operatorname{gr}_{i t+5}=\left(y_{i t+5}-y_{i t}\right) / 5$ is the (annualized) growth rate of country i between period $\mathrm{t}$ and $\mathrm{t}+5, \alpha_{i}$ are invariant, nation specific effects, $y_{i t}$ is the natural log of per capita GDP, gini $_{i t}$ is the gini coefficient for country $\mathrm{i}$ during period $\mathrm{t}, k(\bullet)$ is a general function, $X_{i t}$ is the set of remaining conditioning variables, and $\varepsilon_{i t}$ are time varying shocks. ${ }^{5}$ When the gini coefficient is expressed on a 100-point scale, $k:[-100,+100] \mapsto[-1,+\infty)$, that is to say that the function $k(\bullet)$ maps from the change in income inequality (which cannot be smaller than -100 (going from perfect inequality to perfect equality) nor larger than +100 (going from perfect equality to inequality)) onto the change in per capita GDP (which cannot be smaller than $-100 \%$, but can be arbitrarily large). Without loss of generality, the function $k(\bullet)$ can be rewritten as $h\left(\right.$ gini $_{i t}$, gini $\left._{i t-5}\right)$, whereby $h:[0,100] \times[0,100] \mapsto[-1,+\infty)$. Thus $(2.1)$ can be more generally expressed as:

$$
g r_{i t+5}=\alpha_{i}+\beta_{1} y_{i t}+h\left(\text { gini }_{i t}, g_{i n i} i_{i t-5}\right)+X_{i t} B+\varepsilon_{i t}
$$

Therefore, if one wishes to capture the effects of political processes on subsequent economic performance, a general model like equation (2.2) is appropriate.

\subsection{Growth Model with Capital-Skill Complementarity}

Galor and Moav (2002) develop a growth model whereby the simultaneous and asymmetric accumulation of physical and human capital drives both the development process and the distribution of income. Within the context of their model, they find that during the initial stages of development (when it assumed that both physical and human capital are scarce), income inequality promotes growth because it channels 
resources to wealthier households (who are assumed to have a higher marginal propensity to save), which raises aggregate savings and stimulates capital formation. As the economy develops and the capital stock rises, assumed complementarities between physical and human capital increase the relative importance of human capital necessary for sustained growth. As a result, higher income inequality becomes a hindrance to growth, because it retards human capital formation (assuming the presence of credit market constraints). Therefore, during this intermediate stage of development, higher growth rates would be associated with lower levels of income inequality. Finally, in the latter stages of development, wages rise and marginal propensities to save begin equalize across households, thereby reducing both the importance credit market constraints (and thus the benefits of lower inequality) and the importance of wealthier households in the capital formation process (and thus the benefits of higher inequality). ${ }^{6}$ The implications of this growth model are therefore consistent with an empirical growth model of the following form:

$$
g r_{i t+5}=\alpha_{i}+\beta_{1} y_{i t}+\kappa\left(g_{i n i}, i n v_{i t}\right)+X_{i t} B+\varepsilon_{i t}
$$

where the variables are defined analogously to those in equation $(2.1)$, inv $v_{i t}$ is the relative size of investment (as a percentage of GDP) and the function $\kappa(\bullet)$ captures the nonlinear relationship between growth and inequality, which because of factor input complementarities depends upon the breadth and scope of capital markets (as captured by inv $\left.v_{i t}\right)$.

In order to simultaneously model the net effects of these alternative processes, equations (2.2) and (2.3) can be nested together to form the following general, empirical growth model:

$$
g r_{i t+5}=\alpha_{i}+\beta_{1} y_{i t}+m\left(\text { gini }_{i t}, \operatorname{gini}_{i t-5}, i n v_{i t}\right)+X_{i t} B+\varepsilon_{i t}
$$

where $m(\bullet)$ captures the net, collective effects of a broad class of political economy and traditional growth models. Owing to the generality of the above model, equation (2.4) is thus the focus of investigation in this paper. 


\section{Data Set and Initial Model Estimation}

\subsection{Data}

Conforming to Banerjee and Duflo (2003), Forbes (2000), et. al., this paper makes use of the Deininger and Squire dataset. The remaining dataset values were acquired from various sources, including the Penn World tables, World Bank Development Indicators, the Barro and Lee dataset, etc. A complete listing of the data sources is provided in Table 1A in Appendix A. Throughout the remainder of the paper, the dependent variable will consist of 5-year growth rates, whereas the independent variables will consist of beginning of period values or period averages. The panel consists of 246 observations, with a total of 29 nations in the panel, and observations per nation ranging from a low of 3 to a high of 26. A complete listing of these nations and the years included is provided in Table 2A in Appendix A.

\subsection{Linear Model Estimation}

Before estimating equation (2.4), a short exposition of the empirical properties (and deficiencies) of the basic linear fixed effect growth model is instructive. Thus equation (3.1) below is a linear version of equation (2.4) that uses conditioning variables $\left(X_{i t}\right)$ very similar to Barro $\left.(2000)\right)^{7}$

$$
g r_{i t+5}=\alpha_{i}+\eta_{t}+\beta_{1} y_{i t}+\beta_{2} \operatorname{gini}_{i t}+\beta_{3} i n v_{i t}+X_{i t} B+\varepsilon_{i t}
$$

where the variables are defined analogously to those in equation (2.1), $\eta_{t}$ are time period dummies, and $X_{i t}$ is the set of remaining conditioning variables, including the square of per capita GDP, average years of secondary education (among males aged 15 and higher), the fertility rate, the growth rate of the terms of trade, the rate of inflation, and government expenditures (as a fraction of GDP), and $\varepsilon_{i t}$ are independent and identically distributed shocks. ${ }^{8}$

A scatter plot of the residuals from this model against the gini coefficient is provided in Figure 1 (see Appendix B). ${ }^{9}$ Clearly, the volatility of these residuals is an increasing function of the level of inequality. Two likely explanations are either 1) nations with higher inequality experience greater volatility in their growth rates (i.e. growth rates display heteroskedasticity) or 2) there is a more complicated, nonlinear

relationship between growth and inequality that has been neglected. It is the contention of this paper that this pattern in the residuals is the result of neglected 
nonlinearity as described in Section 2 above. To test the latter hypothesis, a FanUllah (1999) test was utilized.

The Fan-Ullah test is implemented by first obtaining the residuals $\left(\hat{\varepsilon}_{i t+5}\right)$ from the model being tested for neglected non-linearity (i.e. (2.1) above). The conditional expectations of the residuals are then calculated nonparametrically $\left(\hat{E}\left(\hat{u}_{i t+5} \mid \xi_{i t}\right)\right)$, where $\xi_{i t}$ is the variable(s) that potentially effect the dependent variable $\left(g r_{i t+5}\right)$ in a non-linear way. Next, an auxiliary regression is performed in which the original residuals $\left(\hat{\varepsilon}_{i t+5}\right)$ are regressed on their conditionally expected values from the previous step:

$$
\hat{\varepsilon}_{i t+5}=\lambda \cdot \hat{E}\left(\hat{\varepsilon}_{i t+5} \mid \xi_{i t}\right)+v_{i t+5}
$$

Under the null hypothesis of the test, there is no neglected nonlinearity vis-à-vis $\xi_{i t}$. Thus, a simple t-test is performed on the estimated coefficient $\hat{\lambda}$. If $\hat{E}\left(\hat{u}_{i t+5} \mid \xi_{i t}\right)$ is statistically significant, then the null hypothesis that there is no neglected nonlinearity is rejected. Because of the structure of equation 2.4, nonlinearity with respect to the following variables was tested: gini $_{i t}$, gini $_{i t-1}$, $i n v_{i t}$. Table 1 in Appendix $\mathrm{C}$ provides the results of the various Fan-Ullah tests. In every case, the null hypothesis of no neglected nonlinearity is rejected at any standard level of significance, and thus there appears to be a nonlinear relationship between each (and every combination) of these variables and economic performance. In order to more directly examine this nonlinearity and its impact on economic growth, the following section will use semiparametric methods to estimate the general function $m(\bullet)$ from equation 2.4 .

\section{Semiparametric Estimation}

\subsection{Estimation Methodology}

Based on equation (2.4), the following dynamic, fixed effects semiparametric panel model will be estimated:

$$
g r_{i t+5}=\alpha_{i}+\eta_{t}+\beta_{1} y_{i t}+m\left(\text { gini }_{i t}, g_{i n i} i_{i t-1}, i n v_{i t-1}\right)+X_{i t} B+\varepsilon_{i t}
$$


where lagged investment enters the function $m(\bullet)$ instead of base period investment in order to reduce any potential endogeneity. ${ }^{10}$ To begin, equation (4.1) is stacked to form the following:

$$
G R=D^{1} \alpha+D^{2} \eta+\beta_{1} Y+m(Z)+X B+U
$$

where $G R \equiv\left[g r_{16}, g r_{17}, \ldots, g r_{N T+5}\right]^{\prime}, D^{1} \equiv\left[d_{1}^{1}, d_{2}^{1}, \ldots, d_{N}^{1}\right] \quad\left(\right.$ where $d_{j}^{1}$ is an $N T \times 1$ dummy variable vector whose elements corresponding to country $\mathrm{j}$ are equal to 1), $\alpha=\left[\alpha_{1}, \alpha_{2}, \ldots, \alpha_{N}\right]^{\prime}, \quad D^{2}=\left[d_{1}^{2}, d_{2}^{2}, \ldots, d_{T}^{2}\right] \quad\left(\right.$ where $d_{\tau}^{2}$ is an $N T \times 1$ dummy variable vector whose elements corresponding to time period $\tau$ are equal to 1 ), $\eta=\left[\eta_{1}, \eta_{2}, \ldots, \eta_{T}\right]^{\prime}, \quad Y \equiv\left[y_{11}, y_{12}, \ldots, y_{N T}\right]^{\prime}, \quad m(Z) \equiv\left[m\left(z_{11}\right), m\left(z_{12}\right), \ldots, m\left(z_{N T}\right)\right]^{\prime}$, $Z_{i t} \equiv\left(\right.$ gini $_{i t}$, gini $\left._{i t-1}, i n v_{i t-1}\right)$, and $X \equiv\left[X_{11}, X_{12}, \ldots, X_{N T}\right]^{\prime} \cdot{ }^{11}$ Following a procedure similar to Mundra (2004), the conditional expectation of each row of (4.2) is taken with respect to its corresponding value of $\mathrm{z}$ using nonparametric kernel estimation: ${ }^{12}$

$$
E(G R \mid Z)=E\left(D^{1} \mid Z\right) \alpha+E\left(D^{2} \mid Z\right) \eta+\beta_{1} E(Y \mid Z)+m(Z)+E(X \mid Z) B
$$

where it is important to point out that:

and,

$$
E\left(D^{1} \mid Z\right)=\left[\begin{array}{ccc}
E\left(d_{1,1}^{1} \mid z_{11}\right) & \cdots & E\left(d_{N, 1}^{1} \mid z_{11}\right) \\
E\left(d_{1,2}^{1} \mid z_{12}\right) & \cdots & E\left(d_{N, 2}^{1} \mid z_{12}\right) \\
\vdots & \ddots & \vdots \\
E\left(d_{1, N T}^{1} \mid z_{N T}\right) & \cdots & E\left(d_{N, N T}^{1} \mid z_{N T}\right)
\end{array}\right]
$$

$$
E\left(D^{2} \mid Z\right)=\left[\begin{array}{ccc}
E\left(d_{1,1}^{2} \mid z_{11}\right) & \cdots & E\left(d_{T, 1}^{2} \mid z_{11}\right) \\
E\left(d_{1,2}^{2} \mid z_{12}\right) & \cdots & E\left(d_{T, 2}^{2} \mid z_{12}\right) \\
\vdots & \ddots & \vdots \\
E\left(d_{1, N T}^{2} \mid z_{N T}\right) & \cdots & E\left(d_{T, N T}^{2} \mid z_{N T}\right)
\end{array}\right]
$$

The elements of matrices (4.4) and (4.5) above correspond to the conditional probability that a randomly chosen observation (from row $r$ of (4.2)) came from a given country (or time period) given the value of the conditioning variables $(\mathrm{z})$. That 
is to say $E\left(d_{j, r}^{1} \mid z\right)=\operatorname{Pr}\left(d_{j, r}^{1}=1 \mid z\right)$ and $E\left(d_{s, r}^{1} \mid z\right)=\operatorname{Pr}\left(d_{s, r}^{1}=1 \mid z\right)$. Thus, for a given nation (i) and time period (t), equation (4.3) can be written as:

$$
E\left(g r_{i t+5} \mid z_{i t}\right)=\sum_{j=1}^{N} \alpha_{j} E\left(d_{j, i t}^{1} \mid z_{i t}\right)+\sum_{s=1}^{T} \eta_{s} E\left(d_{s, i t}^{2} \mid z_{i t}\right)+\beta_{1} E\left(y_{i t} \mid z_{i t}\right)+m\left(z_{i t}\right)+E\left(X_{i t} \mid z_{i t}\right) B(4
$$

Subtracting equations (4.1) and (4.6) yields:

$$
g \bar{r}_{i t+5}=\sum_{j=1}^{N} \alpha_{j} \bar{d}_{j, i t}^{1}+\sum_{s=1}^{T} \eta_{s} \bar{d}_{s, i t}^{2}+\beta_{1} \bar{y}_{i t}+\bar{X}_{i t} B
$$

Given a suitable set of instruments $\left(W_{i t}\right)$, equation (4.7) can be consistently estimated. As such, $\bar{W}=\left(\bar{D}^{1}, \bar{D}^{2}, \bar{Y}_{-1}, \bar{X}_{-1}\right)$, where $Y_{-1}$ and $X_{-1}$ are the one-period lagged values of $Y$ and $X$ respectively, and let $\tilde{X}=\left(\bar{D}^{1}, \bar{D}^{2}, \bar{Y}, \bar{X}\right) .{ }^{13} \quad$ The OLS instrumental variable estimator the just-identified case is thus:

$$
\left(\hat{\alpha}, \hat{\eta}, \hat{\beta}_{1}, \hat{B}\right)^{\prime}=\left(\bar{W}^{\prime} \tilde{X}\right)^{-1} \bar{W}^{\prime} \overline{G R}
$$

It should be noted that the first term of equation (4.7) can be expressed equivalently as $\sum_{j=1}^{N} \alpha_{j} \bar{d}_{j, i t}^{1}=\alpha_{i}-\alpha_{z_{i t}}$, where $\alpha_{z_{i t}} \equiv \sum_{j=1}^{N} \alpha_{j} E\left(d_{j, i t}^{1} \mid z_{i t}\right)$. Likewise, the second term in equation (4.7) can be expressed as $\sum_{s=1}^{T} \eta_{s} \bar{d}_{s, i t}^{2}=\eta_{t}-\eta_{z_{i t}}$, where $\eta_{z_{i t}} \equiv \sum_{s=1}^{T} \eta_{s} E\left(d_{s, i t}^{2} \mid z_{i t}\right)$. As demonstrated in Robinson (1988), the common intercept in a semiparametric model is unidentified. As such, the level of the fixed effects parameters $\left(\alpha_{i}\right)$ in a panel model are unidentified, however, the deviations of the fixed effects parameters from their conditional means (i.e., $\alpha_{i}-\alpha_{z_{i t}}$ ) are identified. Therefore, equation (4.1) will be equivalently represented as:

$$
g r_{i t+5}=\left(\alpha_{i}-\alpha_{z_{i t}}\right)+\left(\eta_{t}-\eta_{z_{i t}}\right)+\beta_{1} y_{i t}+\tilde{m}\left(z_{i t}\right)+X_{i t} B+\varepsilon_{i t}
$$

where $\tilde{m}\left(z_{i t}\right) \equiv \alpha_{z_{i t}}+\eta_{z_{i t}}+m\left(z_{i t}\right)$. Replacing the population parameter values in (4.9) with their consistently estimated values from (4.8) yields:

$$
g \tilde{r}_{i t+5} \equiv g r_{i t+5}-\left(\hat{\alpha}_{i}-\hat{\alpha}_{z_{i t}}\right)-\left(\hat{\eta}_{t}-\hat{\eta}_{z_{i t}}\right)-\hat{\beta}_{1} y_{i t}-X_{i t} \hat{B}=\tilde{m}\left(z_{i t}\right)+u_{i t}
$$


where $\quad \hat{\alpha}_{z_{i t}} \equiv \sum_{j=1}^{N} \hat{\alpha}_{j} \hat{E}\left(d_{j, i t}^{1} \mid z_{i t}\right)$, and $\quad \hat{\eta}_{z_{i t}} \equiv \sum_{s=1}^{T} \hat{\eta}_{s} \hat{E}\left(d_{s, i t}^{2} \mid z_{i t}\right)$. Finally, $\tilde{m}\left(z_{i t}\right) \quad$ can be estimated via local linear least squares by solving the following minimization problem:

$$
\min _{a, b_{1}, b_{2}, b_{3}}\left\{\sum_{i=1}^{N} \sum_{j=1}^{T_{i}}\left[\left(g \tilde{r}_{i j+5}-a(z)-\left(b_{1}(z), b_{2}(z), b_{3}(z)\right) \cdot z_{i j}^{\prime}\right)^{2} \cdot K\left(z_{i j}, z, h\right)\right]\right\}
$$

where $K\left(z_{i j}, z, h\right)=\frac{1}{(2 \pi)^{3 / 2}} \exp \left(-\frac{1}{2}\left[\left(\frac{\text { gini }_{i j}-g i n i}{h_{1}}\right)^{2}+\left(\frac{g i n i_{i j-1}-g i n i}{h_{2}}\right)^{2}+\left(\frac{\text { inv }_{i j-1}-i n v}{h_{3}}\right)^{2}\right]\right)$.

The solution to the foregoing problem is given by:

$$
\left(\hat{a}, \hat{b}_{1}, \hat{b}_{2}, \hat{b}_{3}\right)^{\prime}=\left(\Psi^{\prime} \vec{K} \Psi\right)^{-1} \Psi^{\prime} \vec{K} g \tilde{r}
$$

where,

$$
\begin{aligned}
& \Psi=\left(\begin{array}{ll}
1 & Z
\end{array}\right) \\
& \vec{K}=\operatorname{diag}\left(K\left(z_{11}, z, h\right) \quad \cdots \quad K\left(z_{N T}, z, h\right)\right)
\end{aligned}
$$

Fundamentally, this is a first-order Taylor series approximation of $\tilde{m}\left(z_{i t}\right)$ at some point $z$, whereby the function $a(z)$ is equal to $\tilde{m}(z)-\nabla \tilde{m}(z) \cdot z^{\prime}$, and the slope parameters $\left(b_{1}(z), b_{2}(z), b_{3}(z)\right) \quad$ are the gradient of $\tilde{m}(z) \quad$ (i.e. $\left.\nabla \tilde{m}(z)=\left(b_{1}(z), b_{2}(z), b_{3}(z)\right)\right) . \quad$ Hence, $\quad \hat{\tilde{m}}(z)=\hat{a}(z)+\left(\hat{b}_{1}(z), \hat{b}_{2}(z), \hat{b}_{3}(z)\right) \cdot z^{\prime} . \quad$ These functions are estimated and analyzed in the following sections.

\subsection{Estimation Results - Linear Coefficients}

Following the estimation procedure outlined above, the linear coefficients of the model were estimated and the slope coefficients (i.e., $\hat{\beta}_{1}, \hat{B}$ ) are provided in Table 2 in Appendix C. Clearly, the estimated coefficients from this model are similar to Barro (2000) and Forbes (2000). Regarding this paper and Barro (2000), both models strongly support conditional convergence. Moreover, both models predict that higher government expenditures (as a fraction of GDP), and higher inflation are growth reducing, while both models agree that improvement in the terms of trade is growth promoting. However, these models are in disagreement regarding the impact of 
fertility on growth. Barro's model predicts that fertility is growth reducing, while the present paper counter-intuitively predicts that fertility is growth promoting. With regard to the present paper and Forbes (2000), both models predict that education (as measured by years of male secondary education) is growth reducing. ${ }^{14}$

\subsection{Estimation Results - The Impact of Inequality on Growth}

In order to estimate the impact of changes in base period inequality on subsequent economic growth (i.e. to estimate $\left.b_{1}(z)=\partial / \partial g i n i_{i t}\left[g r_{i t+5}\right]_{z}\right)$, fixed values of lagged inequality and investment must be chosen. In an attempt to determine economically interesting values for gini $_{i t-1}$ and $i n v_{i t-1}$, all available base-period data from the 1980s were ranked from poorest to richest nation (in terms of per-capita GDP), and the mean values of inequality and investment were determined for the poorest $20 \%$, all nations, and the richest $20 \%$, respectively. The results are provided in Table 3 in Appendix C. Using these three sets of average values, the relationship between inequality and subsequent growth was estimated for the typical poor, middleclass, and rich nation. A plot of these estimated values (i.e., $\left.\hat{b}_{1}(z)\right)$ is provided in Figure 2 in Appendix B.

Several important features jump-out from Figure 2. First, poor countries with their correspondingly low capital stocks and low investment rates enjoy a greater boost (or a lower reduction) in output as a result of an increase in income inequality as

compared to rich nations (i.e. $\hat{b}_{1}\left(\right.$ gini, $\left., \overline{\operatorname{gini}}_{\text {poor }}, \overline{\operatorname{inv}}_{\text {poor }}\right)>\hat{b}_{1}\left(\right.$ gini, $\left.\overline{\text { gini }}_{\text {rich }}, \overline{\operatorname{inv}}_{\text {rich }}\right)$ ). Moreover, the marginal impact on growth as a result of higher income inequality is roughly equal in middle income and rich nations (i.e. $\hat{b}_{1}\left(\right.$ gini, $\left.\overline{\text { gini }}_{\text {middle }}, \overline{\text { inv }}_{\text {middle }}\right) \approx \hat{b}_{1}\left(\right.$ gini, $\left.\left.\overline{\text { gini }}_{\text {rich }}, \overline{\text { inv }}_{\text {rich }}\right)\right)$. Both of these facts are consistent with the implications of the Galor and Moav (2002) growth model. More specifically, inequality is more conducive to growth in lesser developed countries as it channels resources to households who are more likely to augment domestic capital formation. But, in more developed (middle income and wealthy) nations, human capital is relatively more important in the growth process as compared to physical capital, and thus the benefits (if any) of higher income inequality are apt to be smaller.

The second major feature of Figure 2 is that the threshold levels of inequality, beyond which higher inequality becomes growth reducing, roughly correspond to the 
average level of inequality for that group. That is to say, the average level of inequality in poor nations is 38.87, and the level of inequality at which point $\hat{b}_{1}\left(\right.$ gini, $\left.\overline{\operatorname{gini}}_{\text {poor }}, \overline{\operatorname{inv}}_{\text {poor }}\right) \approx 0$ is 36.7 . Likewise, the average level of inequality in all nations is 36.88 , and the level of inequality at which point $\hat{b}_{1}\left(\right.$ gini, $\left., \overline{\text { gini }}_{\text {middle }}, \overline{\operatorname{inv}}_{\text {middle }}\right) \approx 0$ is 33.88. Finally, the average level of inequality in rich nations is 34.53, and the level of inequality at which point $\hat{b}_{1}\left(\right.$ gini, $\left.\overline{\operatorname{gini}}_{\text {rich }}, \overline{\operatorname{inv}}_{\text {rich }}\right) \approx 0$ is 33.49 . In other words, the results of this paper support both the results of Banerjee and Duflo (2003) and the elementary political economy bargaining model in so far as increases in inequality are growth reducing. However, the results of this paper depart from the results of foregoing in that sufficiently large reductions in income inequality are growth promoting. This result is more clearly seen when the values of $\hat{b}_{1}(z)$ from Figure 2 are plotted against their corresponding changes in inequality (i.e. gini $-\overline{\operatorname{gin}}{ }_{\text {poor }}, g$ gini $-\overline{\operatorname{gin}}_{\text {middle }}$, gini-gini $\left.{ }_{\text {rich }}\right) . \quad$ The first of these plots $\left(\hat{b}_{1}\left(\right.\right.$ gini $\left., \overline{\operatorname{gini}}_{\text {poor }}, \overline{\operatorname{inv}}_{\text {poor }}\right)$ vs gini $\left.-\overline{\text { gini }}_{\text {poor }}\right)$ is provided in Figure 3. Analogous plots for middle income nations $\left(\hat{b}_{1}\left(\right.\right.$ gini, $\left.\overline{\operatorname{gini}}_{\text {middle }}, \overline{\operatorname{inv}}_{\text {middle }}\right)$ vs gini- $\left.\overline{\text { ginin }}_{\text {middle }}\right)$ and rich nations $\left(\hat{b}_{1}\left(\right.\right.$ gini, $\left., \overline{\operatorname{gini}}_{\text {rich }}, \overline{\operatorname{inv}}_{\text {rich }}\right)$ vs gini $\left.-\overline{\operatorname{gini}}_{\text {rich }}\right)$ are provided in Figures 4 and 5 respectively. ${ }^{15}$ Regardless of income (and hence average inequality or level of investment), either increases in inequality (regardless of magnitude) or small reductions in inequality are associated with lower growth rates. This result is not necessarily inconsistent with a political economy model where constraints are placed on the magnitude of changes in the income distribution. As such, only small, negotiated increases or decreases in inequality are allowed. However, larger changes and technological breakthroughs, not subject to actions of social coalitions, may simultaneously reduce income inequality and raise medium to long-run growth rates. Clearly, more research into this aspect of political economy models is necessary.

\subsection{Estimation Results - The Role of Investment}

To begin, the tenth and ninetieth percentiles of the gini coefficient and investment were determined for the set of all observations from the 1980s. Next, a set of conditioning values were determined for both the gini coefficient and investment, 
starting with their tenth percentile values and were then incremented by one (two in the case of income inequality) until the ninetieth percentiles were reached. Thus, $A_{1}$, which denotes the set of inequality conditioning values, contains the following 15 values: $A_{1}=\{26,28,30, \ldots, 54\}$. The set of all investment conditioning values, $A_{2}$, contains the following 15 values: $A_{2}=\{15,16, \ldots, 29\}$.

Next, the average change in growth as a result of a change in base year inequality was calculated for each combination of the conditioning variables:

$$
\bar{b}_{1}\left(a_{1} \in A_{1}, a_{2} \in A_{2}\right) \equiv \frac{1}{\# A_{1}} \cdot \sum_{\text {gini } \in A_{1}} \hat{b}_{1}\left(\text { gini }, a_{1}, a_{2}\right)
$$

The values $\bar{b}_{1}$ for all the various combinations of the conditioning variables $\left(\left(a_{1}, a_{2}\right) \in A_{1} \times A_{2}\right)$ are provided in Table 4 of Appendix C. Finally, the values of $\bar{b}_{1}$ from equation (4.15) were averaged over all the inequality conditioning variables:

$$
\tilde{b}_{1}\left(a_{2} \in A_{2}\right) \equiv \frac{1}{\# A_{1}} \cdot \sum_{a_{1} \in A_{1}} \bar{b}_{1}\left(a_{1}, a_{2}\right)
$$

The value $\tilde{b}_{1}\left(i n v_{-1}\right)$ can be interpreted to represent the average rate of change in economic growth as a result of a minute change in income inequality, when a particular level of investment prevailed in the previous period (i.e. inv $v_{-1}$ ). A plot of the values of $\tilde{b}_{1}$ over the various values of investment is provided in Figure 6 . The plot is consistent with the predictions of the growth model of Galor and Moav (2002). As investment (and presumably the capital stock) rises, the deleterious effects of higher income inequality are exacerbated. However, as the investment rate becomes substantially large (presumably the capital stock is large and the economy is in the latter stages of development), the ill-effects of higher income inequality subside, as represented by the reversion of $\tilde{b}_{1}\left(i n v_{-1}\right)$ toward zero. 


\section{Conclusion}

Past empirical investigations of the relationship between economic growth and income inequality have yielded a broad set of results, including that income inequality is harmful to growth, beneficial for growth, and inconsequential to growth. Although models, empirical methodology, and datasets have steadily improved, the empirical unit of interest was a single, invariant coefficient on inequality (which entered the various models linearly). Using a nested model consistent with political economy models and growth models with capital-skill complementarity, this paper finds significant evidence to suggest that the relationship between economic growth and inequality is quite complicated and nonlinear. More specifically, higher income inequality reduces subsequent economic growth. However, small reductions in income inequality also reduce growth - only large reductions in income inequality improve economic performance.

This finding is not inconsistent with a simple political economy bargaining model, in that potential reforms/social investment opportunities with substantial growth payoffs may lead to costly haggling, but that the (albeit diminished) resulting growth may still be higher than the previously prevailing growth rate. Alternatively, technological innovation and private investment outside the purview of the social and political bargaining process may lead to both higher economic growth and lower long to medium term income inequality. As a result, the policy implications of this paper differ dramatically from those of the original cross-country growth literature in that while higher inequality is bad for growth, lower inequality is not necessarily good for growth. Only larger reductions in income inequality are apt to raise economic growth rates.

The second contribution of this paper is that it demonstrates how other economic factors, notably the investment rate, might mitigate and influence the relationship between inequality and growth. More specifically, less developed countries with low levels of investment experience lower reductions in their economic growth rate in response to an increase in income inequality as compared to more developed nations. This is consistent with the Galor and Moav (2002) capital-skill complementarity growth model, whereby in the initial stages of development (when it assumed that both physical and human capital are scarce), income inequality promotes growth because it channels resources to wealthier households (who are assumed to have a higher marginal propensity to save), which raises aggregate savings and 
stimulates capital formation. Consistent with the late-stage development properties of the foregoing growth model, this paper also finds that as the investment rate becomes substantially large, the ill-effects of higher income inequality subside. These results suggest that policy makers should be less concerned with income inequality in developing nations, as an unequal distribution of income may stimulate capital formation and help offset the ill-effects of the redistribution of income through political economy mechanisms. Indeed, policies which discourage domestic investment and/or encourage capital flight should be absolutely avoided as they would undermine the albeit smaller, but positive offsetting effects of inequality. 


\section{Appendix A}

\section{Table 1A}

\begin{tabular}{|l|l|}
\hline Variable & Source \\
\hline Real GDP per capita (chain weighted) & Penn World (Mark 5.6) \\
\hline Investment to GDP ratio & Penn World (Mark 5.6) \\
\hline Government expenditure to GDP ratio & World Bank Development Indicators (2001) \\
\hline Inflation rate & World Bank Development Indicators (2001) \\
\hline Fertility rate & World Bank Development Indicators (2001) \\
\hline Growth rate of terms of trade & World Bank Development Indicators (2001) \\
\hline Primary education completion rate & Barro (Barro/Lee Dataset) \\
\hline Gini coefficient & World Bank (Deininger \& Squire Dataset) \\
\hline Rule-of-Law Index & E. Duflo (originally constructed by Barro) \\
\hline
\end{tabular}


Table 2A

\begin{tabular}{lcl} 
Nation & Observations & Years \\
\hline Australia & 8 & $1968-69,1976,1978-79,1981,1985-1986$ \\
Brazil & 5 & $1982-83,1985-1987$ \\
Canada & 14 & $1969,1971,1973-75,1979,1981-87$ \\
Chile & 9 & $1971,1980-1987$ \\
Colombia & 5 & $1970-72,1974,1978$ \\
Costa Rica & 8 & $1969,1971,1977,1979,1981-1983,1986$ \\
Denmark & 3 & $1976,1981,1987$ \\
Spain & 6 & $1973,1975,1980,1985-1987$ \\
Finland & 11 & $1966,1971,1977-1984,1987$ \\
France & 5 & $1965,1970,1975,1979,1984$ \\
United Kingdom & 26 & $1962-1987$ \\
Indonesia & 8 & $1967,1970,1976,1978,1980-81,1984,1987$ \\
India & 5 & $1973,1977,1983,1986-87$ \\
Italy & 12 & $1975-1984,1986-87$ \\
Japan & 20 & $1963-65,1967-82,1985$ \\
Korea, Rep. & 7 & $1969-1971,1976,1980,1982,1985$ \\
Sri Lanka & 6 & $1970,1973,1979-1981,1987$ \\
Mexico & 4 & $1968,1975,1977,1984$ \\
Malaysia & 5 & $1973,1976,1979,1984,1987$ \\
Netherlands & 9 & $1975,1977,1979,1981-83,1985-87$ \\
Norway & 7 & $1967,1973,1976,1979,1984-86$ \\
Pakistan & 6 & $1970-71,1979,1985-87$ \\
Peru & 5 & $1962,1971-72,1981,1986$ \\
Philippines & 3 & $1965,1971,1985$ \\
Sweden & 11 & $1967,1975-76,1980-87$ \\
Thailand & 4 & $1969,1975,1981,1986$ \\
Trinidad and Tobago & 3 & $1971,1976,1981$ \\
United States & 26 & $1962-1987$ \\
Venezuela, RB & 5 & $1977-79,1981,1987$ \\
& & \\
& &
\end{tabular}




\section{Appendix B}

Figure 1

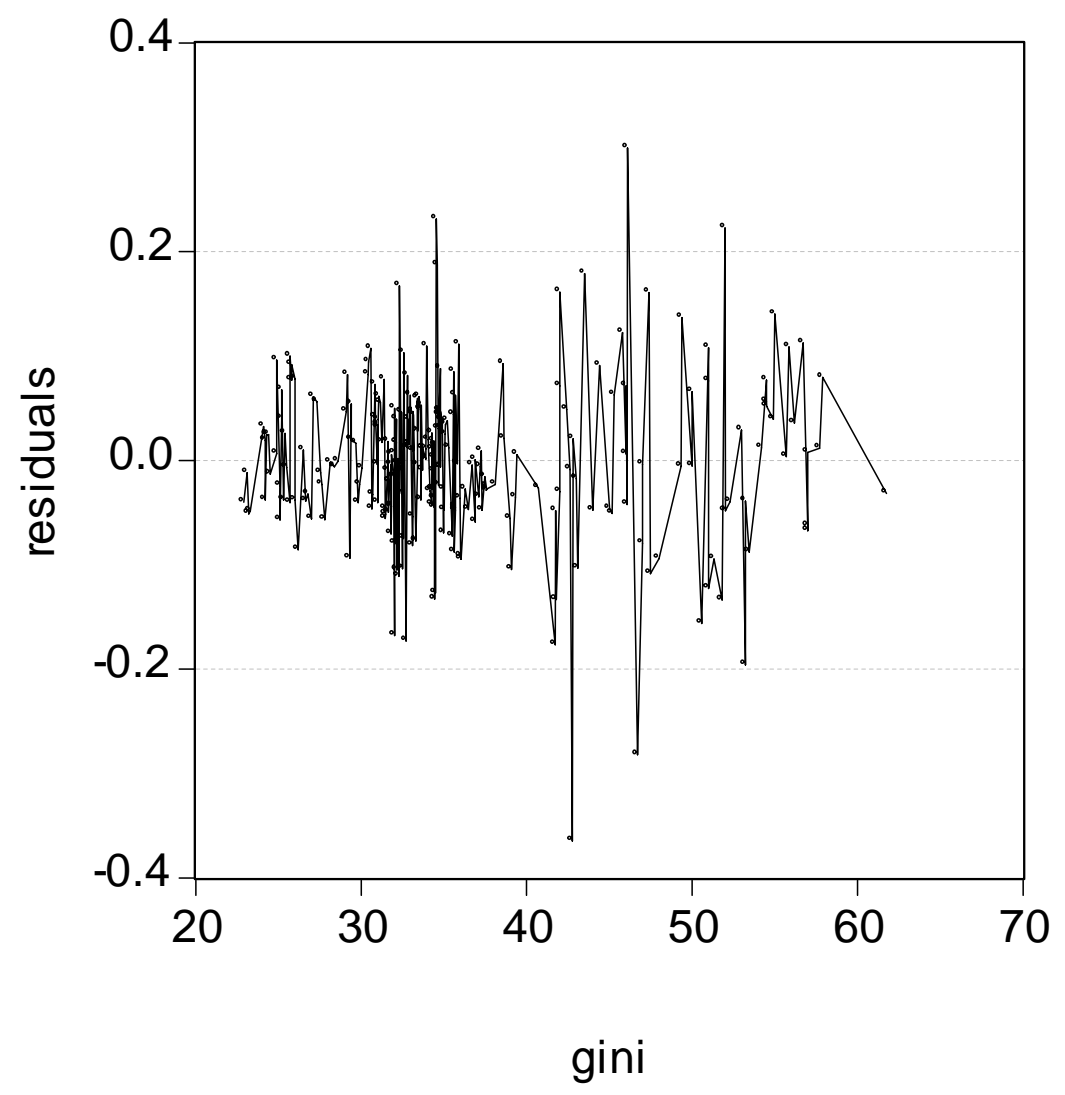


Figure 2

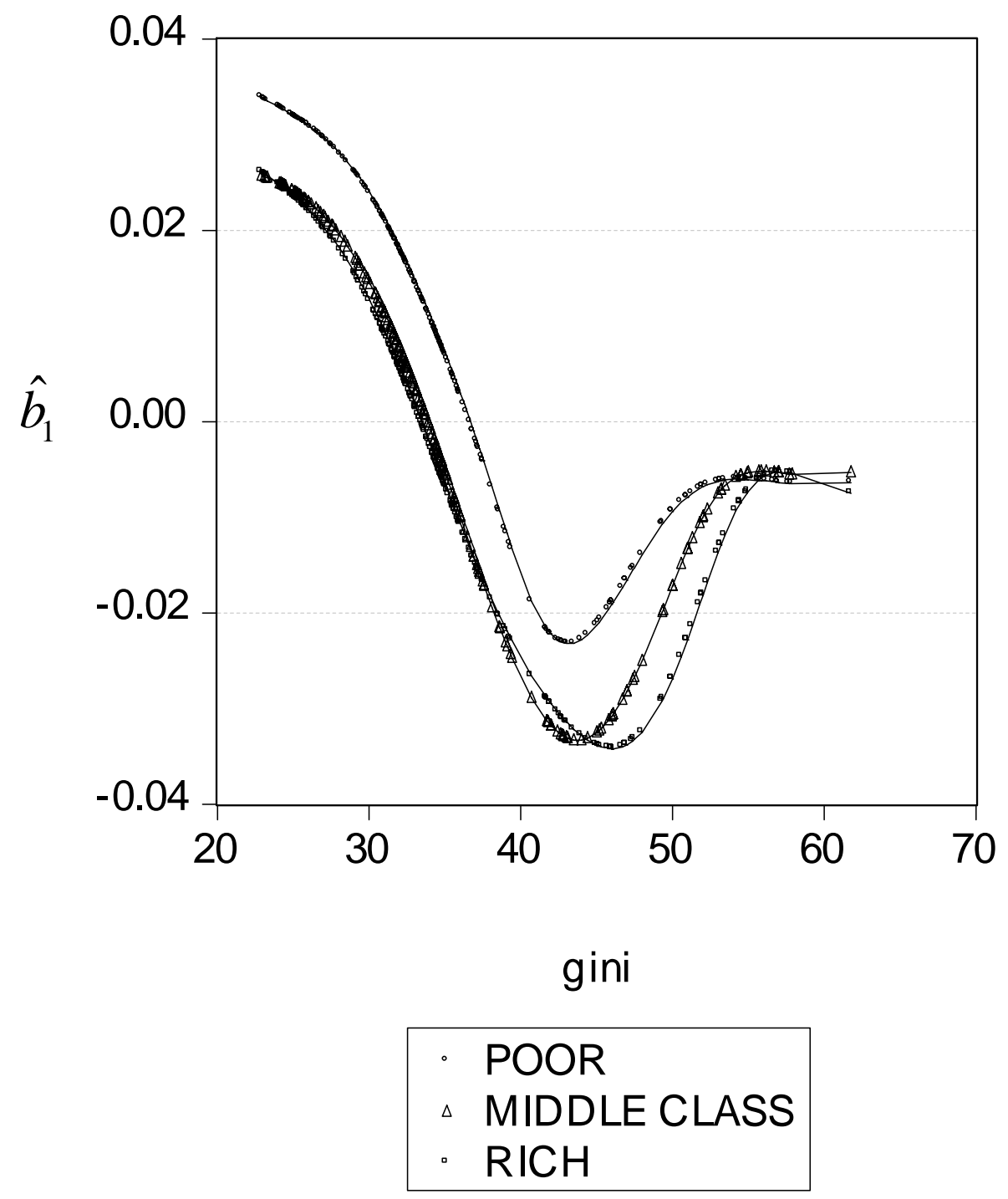


Figure 3

\section{Poor Nations}

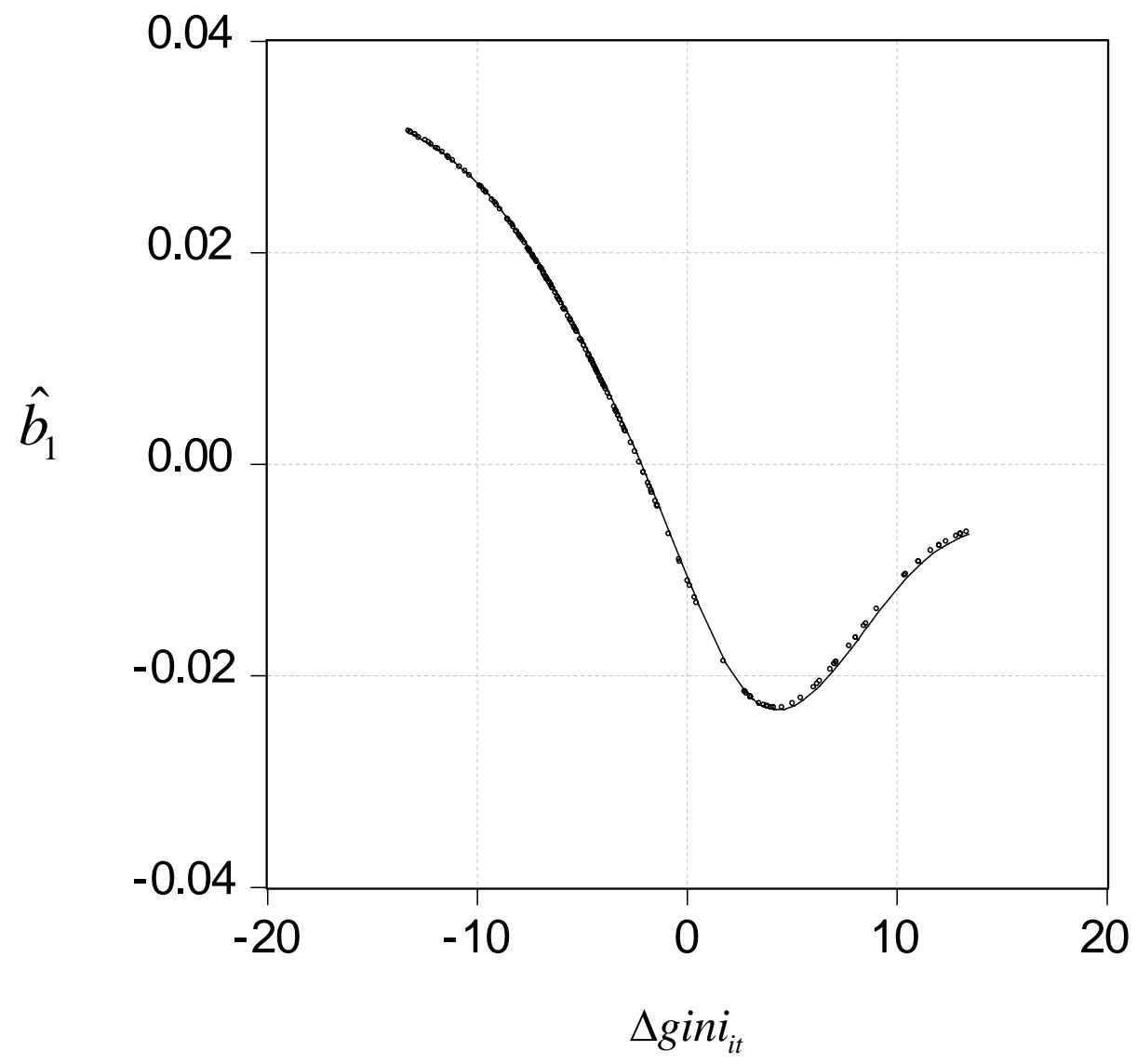


Figure 4

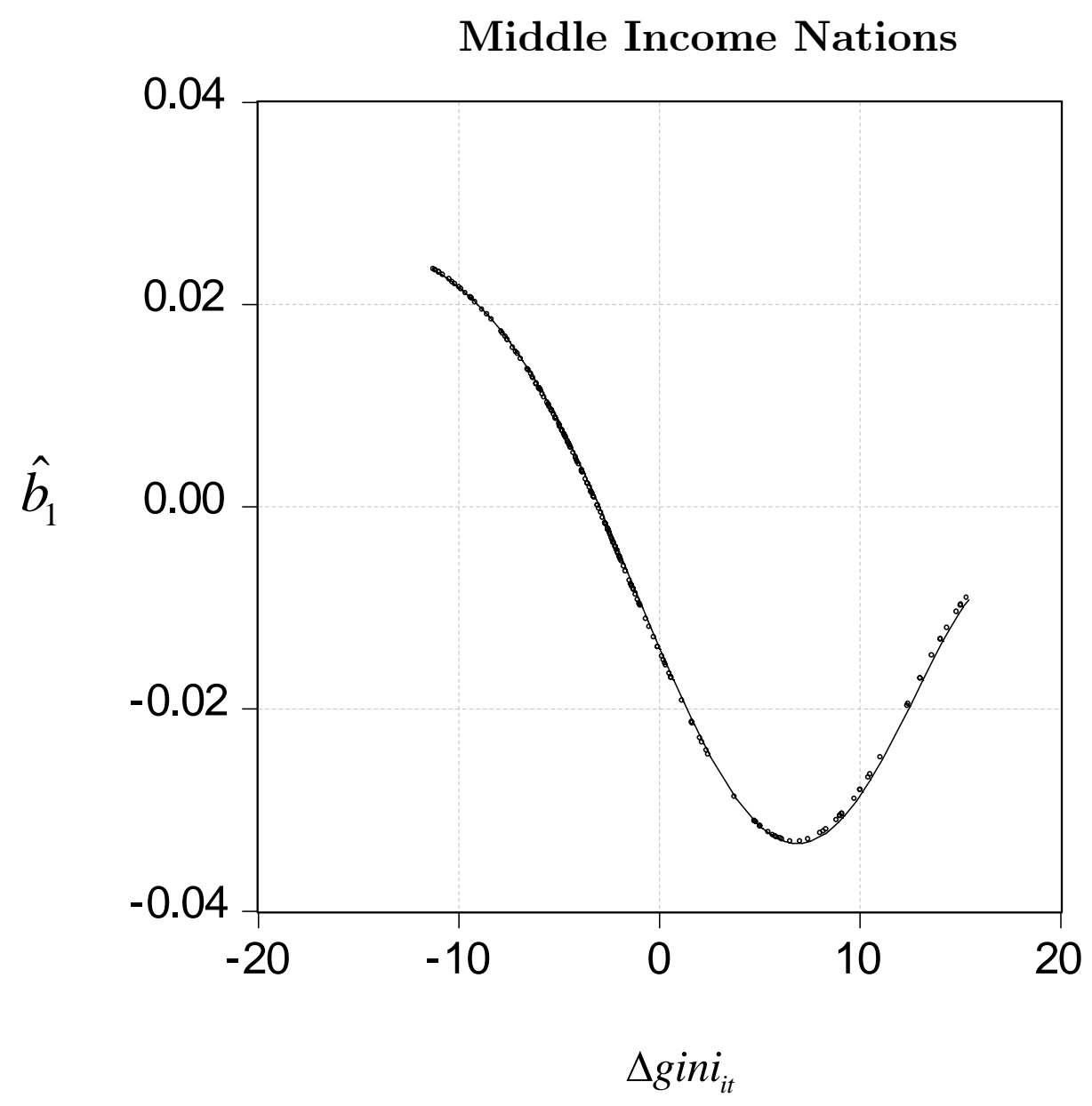


Figure 5

\section{Rich Nations}

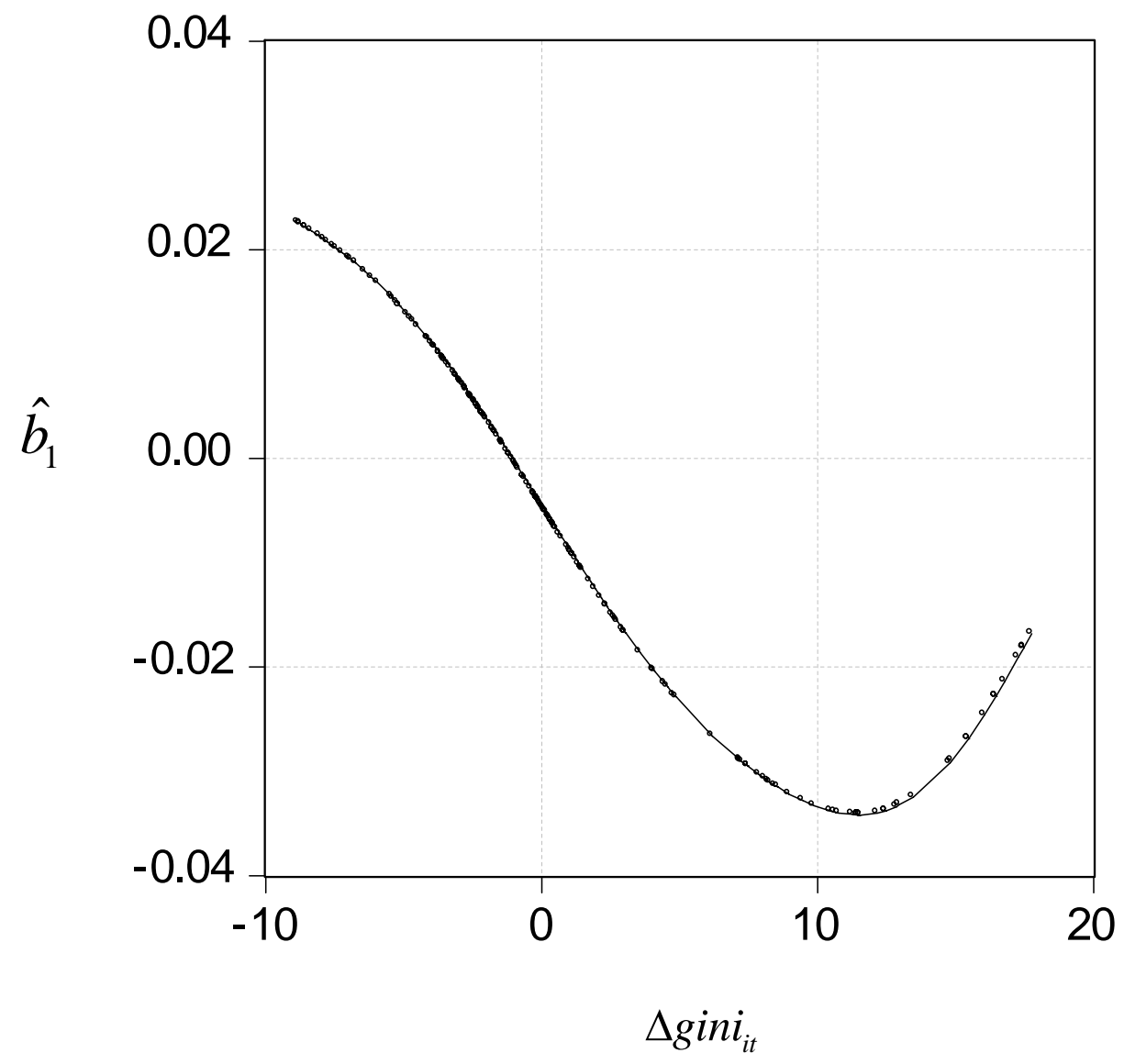


Figure 6

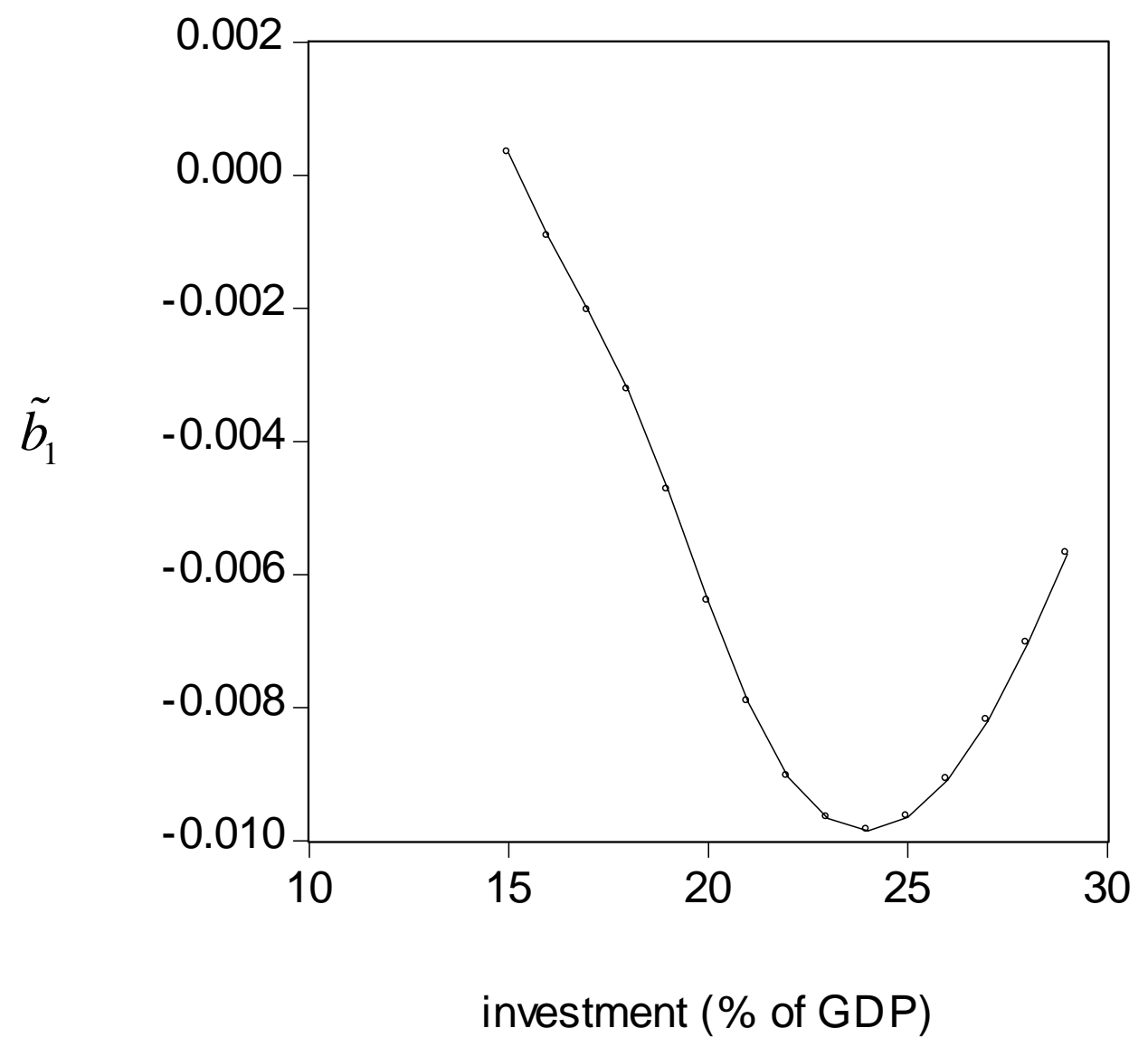




\section{Appendix C}

Table 1

\begin{tabular}{|l|c|}
\hline Conditioning Variable(s) $(\xi)$ & t-statistic \\
\hline gini $_{i t}$ & 2.4369 \\
\hline gini $_{i t-1}$ & 4.6317 \\
\hline inv $_{i t}$ & 3.1435 \\
\hline gini $_{i t}$, inv $_{i t}$ & 7.543 \\
\hline gini $_{i t-1}$, inv $_{i t}$ & 8.5026 \\
\hline gini $_{i t}$, gini $_{i t-1}$ & 6.5034 \\
\hline gini $_{i t}$, gini $_{i t-1}$, inv $_{i t}$ & 12.2661 \\
\hline
\end{tabular}


Table 2

\begin{tabular}{|c|c|c|c|}
\hline Independent Variable & $\begin{array}{l}\text { Barro } \\
(2000) \\
3 S L S\end{array}$ & $\begin{array}{c}\text { Forbes } \\
(2000) \\
\text { FE-GMM }\end{array}$ & $\begin{array}{c}\text { Semi- } \\
\text { Parametric } \\
\text { FE-IV }\end{array}$ \\
\hline \multirow[t]{2}{*}{$\log ($ per capita GDP $)$} & 0.101 & -0.47 & 0.21638 \\
\hline & $(0.030)^{* * *}$ & $(0.008)^{* * *}$ & $(0.03412)^{* * *}$ \\
\hline \multirow[t]{2}{*}{$\log ($ per capita GDP) squared } & -0.0081 & --- & -0.02036 \\
\hline & $(0.0019)^{* * *}$ & & $(0.00204)^{* * *}$ \\
\hline \multirow[t]{2}{*}{ Government consumption/GDP } & -0.153 & ---- & -0.00108 \\
\hline & $(0.027)^{* * *}$ & & $(0.0002)^{* * *}$ \\
\hline \multirow[t]{2}{*}{ Years of schooling } & 0.0066 & --- & --- \\
\hline & $(0.0017)^{* * *}$ & & \\
\hline Education completion rate & --- & --- & --- \\
\hline \multirow[t]{2}{*}{ Years of (male) secondary education } & --- & -0.008 & -0.00584 \\
\hline & & $(0.022)$ & $(0.00126)^{* * *}$ \\
\hline \multirow[t]{2}{*}{ Years of (female) secondary education } & --- & 0.074 & ---- \\
\hline & & $(0.018)^{* * *}$ & \\
\hline \multirow[t]{2}{*}{$\log ($ total fertility rate) } & -0.0303 & --- & 0.01002 \\
\hline & $(0.0054)^{* * *}$ & & $(0.00104)^{* * *}$ \\
\hline \multirow[t]{2}{*}{ Growth rate of terms of trade } & 0.122 & --- & 0.00034 \\
\hline & $(0.035)^{* * *}$ & & $(0.06986)$ \\
\hline \multirow[t]{2}{*}{ Investment/GDP } & 0.062 & --- & --- \\
\hline & $(0.022)^{* * *}$ & & \\
\hline \multirow[t]{2}{*}{ Inflation Rate } & -0.014 & --- & -0.00012 \\
\hline & $(0.009)$ & & $(0.00006)^{* *}$ \\
\hline
\end{tabular}

${ }^{1}$ robust standard errors in parentheses 


\section{Table 3}

\begin{tabular}{|c|c|c|c|}
\hline & $\begin{array}{l}\text { Average } \\
\text { poorest } 20 \%\end{array}$ & $\begin{array}{l}\text { s (1980s) } \\
\text { all nations }\end{array}$ & richest $20 \%$ \\
\hline Log GDP per capita & 7.48 & 8.82 & 9.62 \\
\hline Gini coefficient & 38.87 & 36.88 & 34.53 \\
\hline Investment/GDP (\%) & 15.54 & 21.87 & 23.31 \\
\hline
\end{tabular}


Table 4

investment (\%)

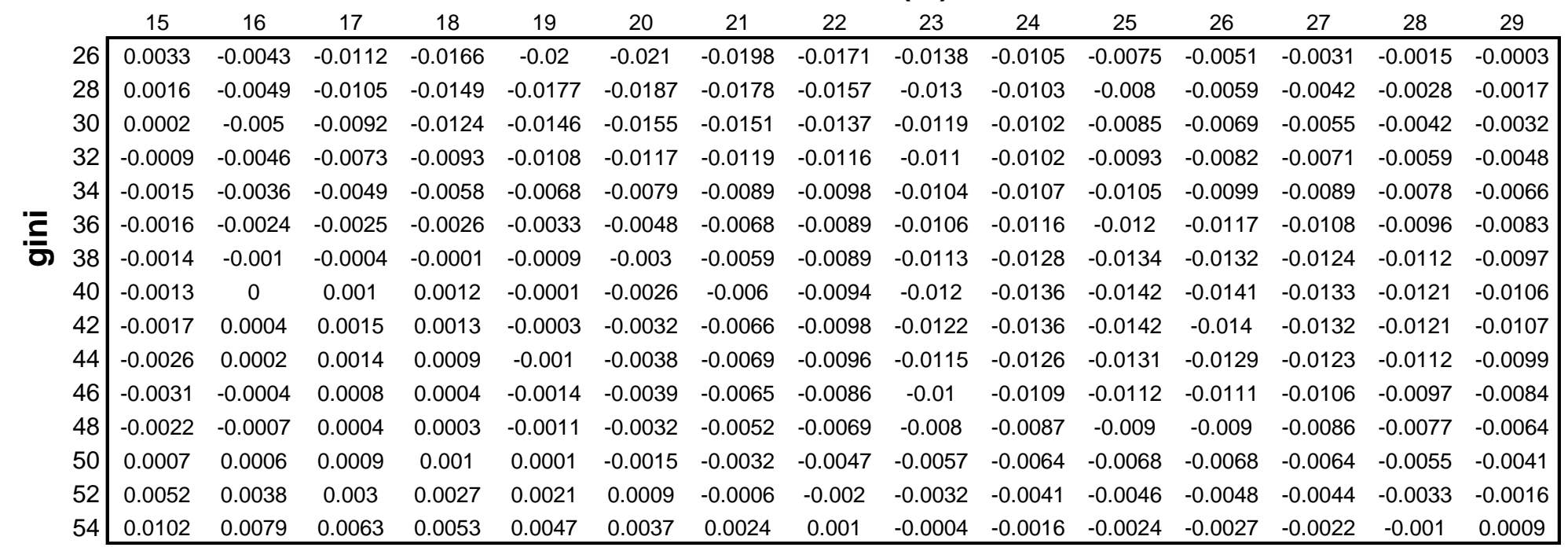




\section{References}

Ahluwalia, M., "Income Distribution and Development," American Economic Review, 66(1976), 128-135.

Alesina, A. and R. Perotti, "Income Distribution, Political Instability and Investment,” European Economic Review, 81(1996), 1170-1189.

Alesina, A. and D. Rodrik, "Distributive Politics and Economic Growth," Quarterly Journal of Economics, 109(1994), 465-490.

Anand, S. and S. M. R. Kanbur, "The Kuznets Process and the InequalityDevelopment Relationship," Journal of Development Economics, 40(1993), 2552 .

Anand, S. and S. M. R. Kanbur, "Inequality and development A critique," Journal of Development Economics, 41(1993), 19-43.

Arellano, M. and S. Bond, "Some Tests of Specification for Panel Data: Monte Carlo Evidence and an Application to Employment Equations," The Review of Economic Studies, 58(1991), 277-297.

Baltagi, B. H., Econometric Analysis of Panel Data, $2^{\text {nd }}$ Ed., (2001), New York: John Wiley \& Sons, LTD.

Banerjee, A. V. and E. Duflo, "Inequality and Growth: What Can the Data Say?" Journal of Economic Growth, 8(2003), 267-299.

Barro, R., "Inequality and Growth in a Panel of Countries," Journal of Economic Growth, 5(2000), 5-32.

Barro, R. and J. W. Lee, “International Measures of Educational Attainment,” Journal of Monetary Economics, 32(1993), 363-394.

Benabou, R., "Heterogeneity, Stratification, and Growth: Macro. Implications of Community Structure and School Finance," American Economic Review, 86(1996), 584-609.

Berg, M. D. and Q. Li and A. Ullah, "Instrumental Variable Estimation of Semiparametric Dynamic Panel Data Models: Monte Carlo Results on Several New and Existing Estimators," Nonstationary Panels, Panel Cointegration and Dynamic Panels, 15(2000), 297-315.

Bertola, G., "Factor Shares and Savings in Endogenous Growth," American Economic Review, 83(1993), 1184-1198.

Caselli, Francesco, Gerardo Esquivel, and Fernando Lefort, "Reopening the Convergence Debate: A New Look at Cross-Country Growth Empirics," Journal of Economics Growth, 3(1996), 363-389. 
Chen, B., "An Inverted-U Relationship Between Inequality and Long-run Growth," Academia Sinica (Taipei, Taiwan) Working Paper, May 2002.

Clarke, G. R., "More Evidence on Income Distribution and Growth," Journal of Development Economics, 47(1995), 403-27.

Deininger, K. and L. Squire, "A New Data Set Measuring Income Inequality," World Bank Economic Review, 10(1996), 565-591.

Deininger, K. and L. Squire, "New Ways of Looking at Old Issues: Inequality and Growth,” Journal of Development Economics, 57(1998), 259-287.

Fan, Y. and A. Ullah, "Asymptotic Normality of a Combined Regression Estimator," Journal of Multivariate Analysis, 71(1999), 191-240.

Fields, G., "Changes in Poverty and Inequality in Developing Countries," World Bank Research Observer, 4(1989), 167-185.

Forbes, K. J., "A Reassessment of the Relationship Between Inequality and Growth," American Economic Review, 90(2000), 869-887.

Galor, O., and O. Moav, "From Physical to Human Capital Accumulation: Inequality and the Process of Development," Review of Economic Studies (forthcoming).

Galor, O., and O. Moav, "From Physical to Human Capital Accumulation: Inequality and the Process of Development," Working Paper (2002).

Galor, O., and D. Tsiddon, "Technological Progress, Mobility, and Economic Growth," The American Economic Review, 87(1997), 363-382.

Galor, O., and J. Zeira, "Income Distribution and Macroeconomics," Review of Economic Studies, 60(1993), 35-52.

Greenwood, J., and B. Jovanavic, "Financial Development, Growth and the Distribution of Income," Journal of Political Economy, 98(1990), 1076-1107.

Hsiao, C., Analysis of Panel Data, (1986), Cambridge: Cambridge University Press.

Jain, S., "Size Distribution of Income: A Comparison of Data," The World Bank, unpublished manuscript, 1975.

Kumar, S. and A. Ullah, "Semiparametric Varying Parameter Panel Data Models: An Application to Estimation of Speed of Convergence," Advances in Econometrics, 14(2000), 109-128.

Kuznets, S., "Economic Growth and Income Inequality," American Economic Review, $45(1955), 1-28$. 
Li, H., L. Squire, and H. Zou, "Explaining International and Intertemporal Variations in Income Inequality,” Economic Journal, 108(1998), 26-43.

Li, H. and H. Zou, "Income Inequality is Not Harmful for Growth: Theory and Evidence," Review of Development Economics, 3(1998), 318-334.

Pagan, A. and A. Ullah, Nonparametric Econometrics, (1999), Cambridge: Cambridge University Press.

Paukert, Felix, "Income Distribution at Different Levels of Development: A Survey of Evidence," International Labour Review, 108(1973), 97-125.

Perotti, R., "Political Equilibrium, Income Distribution and Growth," Review of Economic Studies, 60(1993), 755-776.

Persson, T. and G. Tabellini, "Is Inequality Harmful for Growth," American Economic Review, 84(1994), 600-621.

Robinson, P. M., "Root-N-Consistent Semiparametric Regression," Econometrica, 56(1988), 931-954.

Robinson, S., "A Note on the U-Hypothesis Relating Income Inequality and Economic Development,” American Economic Review, 66(1976), 437-440.

Rodriguez-Campos, M.C. and R. Cao-Abad, "Nonparametric Bootstrap Confidence Intervals for Discrete Regression Functions," Journal of Econometrics, 58(1993), 207-222.

Shao, J. and D. Tu, The Jackknife and Bootstrap, (1995), New York: Springer-Verlag.

Summers, R. and A. Heston, "The Penn World Tables (Mark V): An Expanded Set of International Comparisions, 1950-1988," Quarterly Journal of Economics, 106(1991), 327-368.

World Bank Development Indicators CD (2001). 


\section{Notes}

1 The first empirical papers investigating the link between income inequality and economic growth supported the predictions of the theoretical papers written roughly during the same era (see Greenwood and Jovanovic (1990), Bertola (1993), Galor and Zeira (1993), Perotti (1993), Benabou (1996), Alesina and Perotti (1996)).

${ }^{2} \mathrm{Li}$ and Zou (1998) is an extension of Alesina and Rodrik (1994), while Forbes (2000) is an extension of Perotti (1996).

${ }^{3}$ Forbes (2000) finds that the length of the growth horizon does matter, effecting the sign and/or statistical significance of the coefficient on inequality.

${ }_{4}^{4}$ In addition to Forbes, Li and Zou (1998) demonstrated a positive empirical relationship between inequality and growth using a fixed effects, 5-year panel variant of Alesina and Rodrik (1994).

${ }^{5}$ The control variables used in their include those of Perotti (1996) and Barro (2000).

6 These results critically hinge on three assumptions: 1) "the marginal propensity to save and to bequeath increases with wealth" 2) "the economy is characterized by credit constraints that limit individual's borrowing" and 3) "the economy is characterized by capital-skill complementarity."

7 The Hausman specification test on the linear panel model strongly rejects the random effects specification at any standard level of significance. The Hausman test statistic equals 25.78 , which exceeds the $1 \%$ critical value of 20.09 . Therefore, the fixed-effects specification is used for the remainder of the paper.

${ }^{8}$ Two of Barro's conditioning variables were omitted: democracy and the rule-of-law index. Because this paper employs a fixed effects panel, and the foregoing variables vary little with each country, the economic impact of these variables is captured by the fixed effect coefficients.

${ }^{9}$ Under the assumption that (2.1) is correctly specified, a consistent estimate of the model's parameters was obtained by using the one-period lagged values of the regressors as instruments.

${ }^{10}$ To prevent the loss of a substantial number of observations, one period lagged values of inequality are used instead of five period lags. While this does not introduce any methodological problems, the economic interpretation of $m(\cdot)$ differs somewhat with equation (2.4). Implicitly, the use of shorter lags captures the short-run effect of changes in income inequality on 5-year growth rates, whereas the use of longer lags captures the medium-to-long run impact of changes in income inequality on subsequent 5-year growth.

11 For the sake of ease of exposition, this section assumes a balanced panel of $\mathrm{N}$ countries and $\mathrm{T}$ time periods in order to derive and interpret the meaning of the estimation methods. Substantively, little changes if unbalanced panels are used, but the general exposition of the methods becomes more tedious.

12 Mundra (2004) first replaced the nonparametric function $m(\bullet)$ in her dynamic, semiparametric panel model with a first order Taylor series approximation (thus placing the higher order terms of the approximation in the residuals). Next, she performed a within transformation (expressing each regressor in terms of deviations from country-specific averages), thereby eliminating the country specific fixed effects from her model. Both the current paper and Mundra (2004) use Gaussian product kernels.

${ }^{13}$ Because $\operatorname{rank}\left(D^{1}, D^{2}\right)<N+T$, a column from both $D^{1}$ and $D^{2}$ will be dropped prior to estimation. 
14 As pointed out in Forbes (2000), this counter-intuitive result is common in the development/growth model literature (e.g., see Caselli, et. al. (1996)).

${ }^{15}$ As is typical when plotting nonparametric functions, the lowest and highest $10 \%$ of observations (with respect to inequality) were trimmed from Figures 3 to 5. 